\title{
Heavy metal concentration and toxicity studies on rabbits exposed to Quarry Dust.
}

\author{
Ogbanshi M.E* and Akubugwo E.I \\ Department of Biochemistry, Ebonyi State University, Abakaliki. PMB, 053
}

\begin{abstract}
As part of a detailed study of the heavy metal concentration and the resultant toxicity of quarry dust to quarry workers, the biochemical and hematological changes in rabbit's serum from one to five months of quartz dust inhalation was investigated in Abakaliki quarry industry, Nigeria. The heavy metals present and their concentration in part per million (ppm) were Cadmium (0.06), Lead (0.43), Nickel (0.34), Iron (4740) and Zinc (4.6). A several fold increase in total iron binding capacity was elicited by the dust inhalation. Total white blood cell count was raised in the test group. Lymphocytes, erythrocyte sedimentation rates and monocyte count were also increased by the dust inhalation. Serum proteins such as globulin was elevated but not significant except at five months of exposure. Conversely, the hemoglobin count, neutrophils and packed cell volume decreased significantly in the exposed groups compared to the control from the first month of exposure and intensified as the exposure period increased. The observation shows that an immune reaction is taking place in exposed subjects, leading to a compromise in the immune system of the exposed subjects.

Keyword: Quarry dust, aplastic anemia, hematological parameters and heavy metals
\end{abstract}

\section{Introduction}

Quartz is a frequently occurring solid component of most natural mineral dust. Human exposures to quartz occur most often during occupational activities that involve movement of earth, disturbance of silicon containing product (e.g., masonry, concrete), or use of manufacture of silica-containing product [1]. Environmental exposure to ambient quartz dust can occur during natural, industrial and agricultural activities. Respirable quartz dust particles can be inhaled and deposited in the lung [2]. Inhalation of quartz dust automatically leads to accumulation of some of the heavy metals present in the dust. The term Heavy metals "refer to any metallic element that has a relatively high density and is toxic or poisonous even at low concentrations [4]. Heavy metal is a general collective term which applies to the group of metals and metalloids with atomic density greater than $4 \mathrm{~g} / \mathrm{cm}^{3}$ or 5 times or more great than water [4]. However, being a heavy metal has little to do with density but concerns chemical properties. Quartz dust induces cellular inflammation in vivo [5]. Short term experimental studies of rats have found intratracheal instillation of quartz particles leads to the formation of discrete silicotic nodules in rats, mice and hamsters [6]. Inhalation of aerosolized quartz particles impairs alveolar macrophage clearance functions and leads to progressive lesions and pneumonities [7]. Heavy metals cause a wide range of pathological conditions affecting many organs. Animal studies on copper toxicity have shown varying degrees of liver and kidney damage, decreased total body weight, brain and red blood cell count or gastric ulcer [8]. Cadmium (Cd) has been found to produce a wide range of biochemical and physiological dysfunctions in humans and laboratory animals [9]. The present study aims at assessing the effects of the quartz dust in the blood and on biochemical parameters of rabbits.

\section{Materials and method}

\subsection{Materials}

Adult male rabbits weighing $800-1500 \mathrm{~g}$ were used throughout the study. The animals were divided into two groups, each group containing five rabbits. The test groups were exposed to quarry dust to inhale the dust and its particulate matter at quarry site in Eze-agu mine in Izzi Local Government Area of Ebonyi State, Nigeria. Control groups were housed in an environment free from the dust particle. The study was carried out for the period of five months.

\subsection{Collection of blood samples}

The blood samples were obtained from the ear vein with $2 \mathrm{mls}$ syringe to reduce pain. The blood samples were always collected two times every months and biochemical analysis were carried out.

2.3 Determination of PCV as described by [10]: The EDTA blood sample from each subject was aspirated into micro-hematocrit capillary tubes. One end of the capillary tube was subsequently sealed with plastercin and 
placed in the micro-hematocrit centrifuge. The gradual packing of the red blood cells was induced with a centrifugation speed of $12000 \mathrm{~g}$ for about $5 \mathrm{~min}$. The PCV was measured using a hematocrit reader.

2.4 Determination of WBC as described by [10]: $20 \mu$ of EDTA blood of each subject was added to the labeled test tube containing $0.38 \mathrm{ml}$ of Turk's solution respectively. The solution was allowed to stand for $5 \mathrm{~min}$ and through capillary action; the mixture was introduced into charged new improved neubauer chamber. The population of WBC in the four corner cells was read under the microscope using $\mathrm{x} 10$ objective lens.

2.5 Determination of total iron binding capacity (TIBC): The procedure of [11] was used to determine TIBC. $2 \mathrm{ML}$ of solution containing approximately $50 \mu \mathrm{g}$ of ferric iron per $100 \mathrm{ml}$ was introduced into $1 \mathrm{ml}$ of serum in centrifuge tube and the solution was mixed. $5 \mathrm{~min}$ later, $200 \mathrm{mg}$ light magnesium carbonate was added .The mixture was shaken at interval of 30 to $60 \mathrm{~min}$ and then centrifuged at 300rpm for $5 \mathrm{~min}$ and a portion of the supernatant fluid was decanted into an auto-analyzer cup and estimated as for serum iron. The TIBC was three times the value calculated.

2.6 Determination of $\mathbf{H b}$ and globulin: The $\mathrm{Hb}$ was determined using the method of [12] while reagent kits (Randox laboratory Ltd. UK) was used to determine the globulin. The procedure in the kits was strictly followed.

2.7 Statistics: The result was analyzed statistically. Student's test and one way analysis of variance (ANOVA) were used to compare. The analysis was performed with the use of statistical package for social science (SPSS) statistical software package, version 13.0. $\mathrm{p}<0.05$ was considered statistically significant

III. Results:

(TABLE 1).Concentrations of heavy metals present in quarry dust and their percentage oxides.

\begin{tabular}{lll}
\hline Element & Concentrations $(\mathrm{ppm})$ & \% oxides \\
\hline Cadmium $(\mathrm{Cd})$ & 0.06 & 0.00178 \\
Cupper $(\mathrm{Cu})$ & 0.28 & - \\
& & \\
Lead $(\mathrm{Pb})$ & 0.43 & - \\
Nickel $(\mathrm{Ni})$ & 0.34 & - \\
Iron $(\mathrm{Fe})$ & 4740 & 0.34 \\
Zinc $(\mathrm{Zn})$ & 4.6 & - \\
Silicon $(\mathrm{Si})$ & - & 69 \\
\hline
\end{tabular}

(TABLE 2). Comparison of total white blood cell count (WBC) and the differential count of quarry dust exposed rabbits with the control

\begin{tabular}{|c|c|c|c|c|c|}
\hline & & PERIOD & OF & EXPOSURE & \\
\hline PARAMETER & FIRST MONTH & $\begin{array}{l}\text { SECOND } \\
\text { MONTHS }\end{array}$ & THRD MONTHS & $\begin{array}{l}\text { FOURTH } \\
\text { MONTHS }\end{array}$ & FIFT MONTHS \\
\hline \multicolumn{6}{|l|}{$\begin{array}{l}\text { Total WBC } \quad(x \\
\left.10^{9} / \mathrm{L}\right)\end{array}$} \\
\hline $\mathrm{QE}$ & $12.43 \pm 2.76$ & $17.43 \pm 2.14 *$ & $18.00 \pm 0.47 *$ & $18.25 \pm 2.06^{*}$ & $19.00 \pm 3.00 *$ \\
\hline $\mathrm{C}$ & $10.40 \pm 0.34$ & $10.44 \pm 1.02$ & $10.33 \pm 0.47$ & $11.40 \pm 1.02$ & $10.42 \pm 1.03$ \\
\hline \multicolumn{6}{|l|}{$\begin{array}{l}\text { Neutrophils (x } \\
10^{9} / \mathrm{L} \text { ) }\end{array}$} \\
\hline $\mathrm{QE}$ & $30.33 \pm 1.53 *$ & $31.67 \pm 1.24 *$ & $28.33 \pm 2.71 *$ & $28.34 \pm 2.72 *$ & $25.22 \pm 3.80 *$ \\
\hline $\mathrm{C}$ & $49.67 \pm 2.24$ & $51.67 \pm 3.35$ & $52.67 \pm 3.49$ & $52.71 \pm 2.49$ & $52.70 \pm 4.50$ \\
\hline \multicolumn{6}{|l|}{$\begin{array}{l}\text { Lymphocytes (x } \\
10^{9} / \mathrm{L} \text { ) }\end{array}$} \\
\hline $\mathrm{QE}$ & $60.00 \pm 0.75^{*}$ & $62.33 \pm 7.36^{*}$ & $63.33 \pm 6.55^{*}$ & $64.36 \pm 6.56^{*}$ & $66.00 \pm 6.80 *$ \\
\hline $\mathrm{C}$ & $45.00 \pm 4.08$ & $45.33 \pm 4.18$ & $46.03 \pm 4.08$ & $45.04 \pm 4.02$ & $45.20 \pm 5.00$ \\
\hline \multicolumn{6}{|l|}{$\begin{array}{l}\text { Monocyte (x } \\
\left.10^{9} / \mathrm{L}\right)\end{array}$} \\
\hline $\mathrm{QE}$ & $6.33 \pm 3.09$ & $10.67 \pm 1.60 *$ & $10.72 \pm 1.69 *$ & $10.69 \pm 1.70 *$ & $10.70 \pm 1.71^{*}$ \\
\hline $\mathrm{C}$ & $2.33 \pm 1.69$ & $1.00 \pm 1.41$ & $1.30 \pm 1.00$ & $1.32 \pm 1.01$ & $1.28 \pm 0.95$ \\
\hline \multicolumn{6}{|l|}{$\begin{array}{l}\text { Eosinophils (x } \\
\left.10^{9} / \mathrm{L}\right)\end{array}$} \\
\hline $\mathrm{QE}$ & $6.74 \pm 3.92 *$ & $6.40 \pm 2.5^{*}$ & $6.00 \pm 2.7 *$ & $3.70 \pm 2.81 *$ & $3.40 \pm 2.80 *$ \\
\hline $\mathrm{C}$ & $0.6 \pm 0.6$ & $0.62 \pm 0.92$ & $0.56 \pm 0.71$ & $0.4 \pm 0.80$ & $0.4 \pm 0.78$ \\
\hline
\end{tabular}


$\mathrm{QE}=$ Exposed groups, $\mathrm{C}=$ Control groups. Values bearing the superscripts $*$ is significantly different from the controls.

(TABLE 3). Comparison of means of values of hemoglobin count (Hb), packed cell volume (PCV), erythrocytes sedimentation rate (ESR), total iron binding capacity (TIBC) and globulin.

\begin{tabular}{|c|c|c|c|c|c|}
\hline \multicolumn{6}{|c|}{ PERIOD OF EXPOSURE } \\
\hline PARAMETER & FIRST MONTH & SECOND MONTHS & THIRD MONTHS & FOURTH MONTHS & FIFT MONTHS \\
\hline $\mathrm{Hb}\left(\times 10^{12} / \mathrm{L}\right)$ & & & & & $9.24 \pm 1.07 *$ \\
\hline $\mathrm{QE}$ & $11.8 \pm 1.70 *$ & $11.67 \pm 1.05 *$ & $10.80 \pm 1.42 *$ & $9.81 \pm 1.40^{*}$ & $23.01 \pm 1.72$ \\
\hline $\mathrm{C}$ & $22.2 \pm 1.92$ & $23.03 \pm 1.72$ & $23.47 \pm 2.04$ & $23.48 \pm 2.03$ & \\
\hline \multicolumn{6}{|l|}{$\operatorname{PCV}(\%)$} \\
\hline $\mathrm{QE}$ & $40.33 \pm 3.11 *$ & $43.32 \pm 2.01 *$ & $43.30 \pm 2.51^{*}$ & $42.00 \pm 1.82 *$ & $43.33 \pm 1.72 *$ \\
\hline $\mathrm{C}$ & $55.00 \pm 4.08$ & $62.33 \pm 2.05$ & $63.67 \pm 3.62$ & $63.68 \pm 2.63$ & $62.70 \pm 2.64$ \\
\hline \multicolumn{6}{|l|}{ ESR (hrs) } \\
\hline QE & $4.33 \pm 1.25 *$ & $4.00 \pm 0.82 *$ & $4.21 \pm 1.22 *$ & $4.32 \pm 1.19 *$ & $4.34 \pm 1.26^{*}$ \\
\hline $\mathrm{C}$ & $1.67 \pm 0.47$ & $1.66 \pm 0.47$ & $1.62 \pm 0.44$ & $1.68 \pm 0.30$ & $1.60 \pm 0.40$ \\
\hline \multicolumn{6}{|l|}{ TIBC $(\mu \mathrm{g} / \mathrm{d})$} \\
\hline \multicolumn{6}{|l|}{ QE } \\
\hline \multirow[t]{2}{*}{$\mathrm{C}$} & $100.84 \pm 5.5$ & $104.30 \pm 19.9 *$ & $106.96 \pm 22.36^{*}$ & $110.50 \pm 20.0 *$ & $118.60 \pm 21.02 *$ \\
\hline & $100.26 \pm 9.0$ & $100.09 \pm 13.0$ & $100.07 \pm 14.0$ & $100.00 \pm 11.2$ & $101.60 \pm 21.0$ \\
\hline \multicolumn{6}{|l|}{ Globulin } \\
\hline QE & $1.71 \pm 0.70$ & $2.07 \pm 0.34$ & $2.00 \pm 0.56$ & $2.40 \pm 0.97$ & $2.32 \pm 0.76 *$ \\
\hline $\mathrm{C}$ & $2.42 \pm 0.48$ & $2.34 \pm 0.28$ & $2.19 \pm 0.67$ & $2.24 \pm 8.4$ & $3.13 \pm 0.45$ \\
\hline
\end{tabular}

$\mathrm{QE}=$ Quarry dust exposed groups. $\mathrm{C}=$ Control groups. Values bearing the superscripts * are statistically significant from the control.

\section{Discussion}

In the presence of infections, T-WBC would normally be raised [10]. This rise in T-WBC enables the body to overcome invading pathogen. The WBC was significantly raised in the exposed group in this case, suggesting that the quarry dust may have been inhaled into the lungs of the exposed groups as particulate matter and as such, the T-WBC was mobilized to fight against the invading foreign agents. A reduction in circulating neutrophils is usually observed in the case of bone marrow failure, viral infections, some autoimmune diseases, use of some drugs such as chemotherapeutic agents [10]. In the presence of an infections in the blood, neutrophils are usually increase, this is because they are the major phagocytosizing cells in the blood [12] and are the first cell type to be recruited into the site of infections. A reduction in the neutrophil number therefore indicates that the quarry dust inhalation could result to an individual having reduced ability to fight infections. The lymphocytes number increased in the exposed group confirming the fact that there is an infection in this case by quarry dust which was inhaled. Usually, increases in the number of lymphocytes are observed in the case of viral and bacterial infection [10]. The present increase in lymphocytes is a result of the quarry dust inhalation. An increase was also observed in the number of eosinophils and monocytes in the test groups. This increase known as eosinophilia [13] in the case on eosinophil increase is usually seen in the allergic conditions, such as asthma, hay fever and use of chemotherapeutic agents [14]. Low HB and PCV are both indices of anemia [10]. These indices are both reduced in the exposed groups. It is highly probable that exposure to quarry dust is implicated since it has been reported that some conditions such as exposure to chemicals, insecticides, ionizing radiations, some drugs (Chloramphenicol and cytotoxic drugs),infections (viral) have led to the development of aplastic anemia in some individuals [10]. The exposed group also shows decreased neutrophils, these together with low $\mathrm{Hb}$ and PCV are both indices of aplastic anemia. The likelihood therefore exists as seen here that quarry dust inhalation might be a risk factor for aplastic anemia development. The rise in ESR has been described as a nonspecific phenomenon [12]. ESR is raised in several conditions especially during an acute phase response where there is production of acute phase protein in the liver [9]. The rise in globulin which is among the total proteins in the blood encourages rouleax formation and hence the red blood cells sediment at a faster rate [15]. The inhaled quarry dust elicits an inflammatory response [16;17] in the test group hence the raised ESR values observed. The atomic absorption spectrophotometric analysis of the dust revealed the presence of $\mathrm{Cd}$., $\mathrm{Cu}, \mathrm{Pb}, \mathrm{Ni}, \mathrm{Fe}, \mathrm{Zn}$ and $\mathrm{Si}$ with silicon and iron occurring at a higher concentration (table 1). It is very much clear that these exposed groups inhale more of these elements. The total iron binding capacity of the exposed rabbits increased as the period of exposure increased (table 3). Increase in serum iron may indicate increased erythrocyte destruction, decreased erythrocyte formation, increase in iron deficiency anemia and decrease in hemochromatosis, malignancies.

\section{Conclusion}

Hence, quarry dust inhalation might lead to changes in circulating cells and subsequently reduced immunity in occupational worker without protective measures. 


\section{References}

[1]. O Kaylyci, T. Besler, K. Kilnc ,B.E Seceral and Y. Saraclar. Serum levels of antioxidant vitamins (alpha tocopherol, beta carotene and ascorbic acid) in children with bronchial asthma. Journal of pediatrics 42.2000, 17-21.

[2]. E Hnizdo and V. Vallyathan. Chronic obstructive pulmonary disease due to occupational exposure to silica dust: a review of epidemiological-. Occupational and Environmental Medicine 60. 2003, 237-243.

[3]. Lennetch Water Treatment and Air Purification. Water treatment, published by Lennetch, Rotterdamsewey, Netherlands [Online]. 2004. available at www.excelwater.com/thp/filters/water-purification.htm

[4]. J.S Hawkes. Heavy metals. J. Chem. Educ 74(11). 1997, 13744

[5]. Rune, Ragna, Hetland, J. Hans, B. Dahlman and N. Schwart. Rat lung inflammatory responses after in vivo and in vitro exposure to various stone particles. Inhalation Toxicology 13. 2001, 789-805.

[6]. M.F Khan , F.N. Jaffery, S. Ali and Q. Rahman . Biochemical studies on the toxicity of slate mine dust. Environmental Health Perspective 51. 1993, 305-310.

[7]. V Diaz, R. Carlos, C. Garcia, R. Mendoza, I. Hernadez and U. Edgardo . Increased malondialdehyde in peripheral blood of patients with congestive heart failure-. American Heart J 131(1). 1996,146-152.

[8]. C Roberts, and M. Williams. Utah Geological and Mineral Survey. Journal of Medical Association 1(3). 1998,3 -5.

[9]. F.W Santos, T. Oro, N.Z Zeni, J.B Rocha, P.C Nascimento and C.W Nogueira. Cadmium-induced testicular damage and its response to administration of succimer and diphenyl dieseline in mice. Toxicological Letters 152. 2004, 255-263.

[10]. Cheesbrough. District laboratory practice in the tropical countries. Part 2. (Cambridge CB 2 RU, UK 2000), p. 329-331.

[11]. W.N Ramsay. The determination of iron in blood plasma or serum. Clinical chin acta 2(3). 1957, 214-220.

[12]. Dacie and S.M Lewis. Current concert in hematology 3: Blood count calibration. Journal of chlinical pathology 44. $1994,881-884$.

[13]. J.T Zelikoff, K.R Schermerhorn, K. Fang, M.D Cohen and R.B Schlesinger. A role for associated transition metals in immunotoxicity of inhaled ambient particulate matter.Eviron Health Persp 5. 2002, 871-875

[14]. A.E Okorocha and Antai. Alteration of the hematological indices of rats following kerosene fumes exposure- Journal of Biomedical Afric 5.2007, 44-47.

[15]. G.W Osbaldison. Erythrocyte sedimentation studies in Sheep Dog and Horse Cornell Vet 61.1997, 386-399.

[16]. NOISH. Health effects of occupational exposure in respirable cystalline silica. journal of Occupational Health 24. 1996, 10-15.

[17]. R.B Hetland, M. Refsnes, J.E Dahl, H.J Dahlman and P.E Schwarze. Rat lung inflammation and in vitro exposure to various stone particles. Inhalation Toxicol 13. 2001, 789-805. 